Synthesis, part of a Special Feature on The Energy-Water Nexus

\title{
Enhancing the Resilience of the Australian National Electricity Market: Taking a Systems Approach in Policy Development
}

\author{
Barry Newell $^{1}$, Debborah M. Marsh $^{2}$, and Deepak Sharma ${ }^{2}$
}

\begin{abstract}
As the complexity and interconnectedness of present-day social-ecological systems become steadily more apparent, there is increasing pressure on governments, policy makers, and managers to take a systems approach to the challenges facing humanity. However, how can this be done in the face of system complexity and uncertainties? In this paper we briefly discuss practical ways that policy makers can take up the systems challenge. We focus on resilience thinking, and the use of influence diagrams, causal-loop diagrams, and system archetypes. As a case study, set in the context of the climate-energy-water nexus, we use some of these system concepts and tools to carry out an initial exploration of factors that can affect the resilience of the Australian National Electricity Market. We stress the need for the electricity sector to prepare for the impacts of global change by encouraging innovation and diversity, supporting modularity and redundancy, and embracing the need for a policy making approach that takes account of the dynamics of the wider social-ecological system. Finally, taking a longer term view, we conclude by recommending that policy makers work to reduce reliance on conventional market mechanisms, institute continuing crosssector dialogue, and promote basic education in system dynamics.
\end{abstract}

Key Words: Australian National Electricity Market; climate-energy-water nexus; resilience; system analysis; system dynamics

\section{INTRODUCTION}

There is no longer any doubt that human activity is beginning to cause unacceptable change in the Earth system (Steffen et al. 2004, Rockström et al. 2009). Worldwide communities are moving to mitigate anthropogenic impacts and to adapt to those changes that cannot be prevented. In particular, the potential social, economic, and environmental impacts of global climate disruption are high on the public agenda (IPCC 2004, Hansen et al. 2008, Steffen 2009). Concurrently, as awareness of the importance of cross-sector interactions has grown, there have been increasing calls for research groups and policy makers to take a systems approach. This focus can be seen clearly in Grand Challenges in Global Sustainability Research: A Systems Approach to Research Priorities for the Decade, produced by the International Council for Science and The International Social Science Council (ICSU 2010). An Australian example is afforded by the recent report from the Prime Minister's Science, Engineering and Innovation Council (PMSEIC
2010), Challenges at Energy-Water-Carbon Intersections, which strongly advocates a systems perspective with a focus on resilience.

However, it is not easy to take a systems approach in social-ecological systems. Such systems are dynamically complex. That is, their behavior emerges from the interactions between their parts, with the consequence that even a system of relatively few variables can behave in unexpected and highly nonlinear ways (Axelrod and Cohen 1999, Sterman 2000, Scheffer 2009). Even a cursory discussion of which variables and which interactions need to be taken into account leads to a discouragingly long list. Furthermore, there are commonly few data concerning the behavior-overtime of the key variables, and those data that are available are often uncertain. A natural strategy, for policy makers and managers in such situations, is to remain focused on narrowly defined problems that are contained within the sector of most immediate concern. This tendency is strengthened when limited resources, tight deadlines, and 
competition combine to make cross-sector policy making appear impractical and a threat to established power bases.

Nevertheless, the response of a dynamically complex system to a given management initiative cannot be anticipated on the basis of a narrow, inward-looking approach. It is a truism of system science that a system's performance cannot be optimized by optimizing the performance of its subsystems taken in isolation from one another. Detailed studies within sectors can provide essential information concerning the functioning of each sector, but efforts to avoid unwanted policy outcomes and to identify leverage points for effective change must take into account the effect of interactions between the sectors. Divide and conquer approaches may appear to make the policy design task tractable, and do tend to produce policies that work initially, but usually such dynamically simplistic policies fail in the medium to long term (Boyden et al. 1981, Sterman 2000, Meadows 2008). All too often such policy failure is attributed to some proximate external event rather than to shortcomings in the policy itself.

Policy makers, therefore, face an unavoidable dilemma when they work in complex systems. The bounded rationality of human beings makes it inevitable that the policy making process in such systems will always be a somewhat incremental, fragmented process (Lindblom and Woodhouse 1993). However, policy makers who focus exclusively on subsystems, small enough to appear understandable and manageable, inevitably will be surprised by unintended policy outcomes. This is not just an issue of bounded rationality. Recent research has demonstrated that adults, including those who are technically well educated, have poor intuitions concerning the behavior of even simple dynamical systems (Sterman 2008). This lack of basic understanding not only prevents the design of effective cross-sector policies, but also blinds the community to the need for at least a minimum level of dynamical systems literacy in those entrusted with policy design.

Calls for a systems approach thus lead to the practical question: How can policy makers actually take a systems approach in the face of system complexity and the consequent uncertainties and low levels of understanding? In this paper we present a specific, limited response to this question. Our aim is to review and demonstrate some practical methods that can help policy makers to increase their understanding of the dynamics of a given policy situation and so minimize unwanted policy outcomes. After discussing some well-developed system analysis tools, we present a case study that illustrates the use of some of these tools to initiate a systems approach. The case study is focused on ways to approach the design of policies that enhance the resilience of the Australian National Electricity Market. Such considerations are central to efforts to ensure an electricity supply system that is secure and reliable despite disturbances caused, for example, by climate disruption and climate change adaptation and mitigation policies. Finally, we recommend several actions that could enhance the policy making community's ability to take a systems approach.

\section{TAKING A SYSTEMS APPROACH}

In any policy making endeavor the key dynamical question is: What will happen when this policy is implemented? In recent decades the scientific community has taken on the challenge of converting insights from the theory of dynamical systems into practical methods that can help policy makers answer this question. Prominent among these efforts are the work of the Santa Fe Institute (Alexrod and Cohen 1999, Mitchell 2009, Bettencourt and West 2010), the Resilience Alliance (Gunderson and Pritchard 2002, Walker and Salt 2006, Scheffer 2009), and the System Dynamics community (Sterman 2000, Meadows 2008). In this paper we focus particularly on the insights generated by the Resilience Alliance and the System Dynamics community.

\section{Accumulation and feedback}

There is an urgent need for decision makers at all levels throughout the community to recognize that linear models of cause and effect are inadequate. Linear thinkers assume, for example, that if you double the cause you will double the effect. Such thinking can be highly misleading in complex social-ecological systems where causation is driven by accumulation and feedback.

\section{Accumulation}

Accumulation plays a dominant role in the behavior of social-ecological systems, at all temporal, spatial, 
and organizational scales (Cronin et al. 2009). In the System Dynamics literature, accumulations are referred to as 'stocks' and the processes that change the amounts accumulated are called 'flows' (Sterman 2000). Accumulations include things, material and energy, as well as less concrete quantities such as stress and political pressure. They decouple inflow and outflow rates, thus acting as buffers in systems where these rates vary independently, for example, urban water supply systems and the human metabolic system. In addition, accumulation-changing processes operate at finite rates, thereby causing delayed systemresponse to natural changes and human actions. Such delays are sources of inertia in socialecological systems. Delays inhibit experiential learning and introduce uncertainty into the design and implementation of policies (Sterman 2000). From this it follows that timely and effective policy making in complex systems requires a good understanding of the fundamental, unavoidable effects of accumulation.

\section{Feedback}

Feedback is a pervasive and powerful cause and effect mechanism. It operates when a change in an accumulation can feed back, around a cause and effect loop to either amplify or resist the original change. The terms 'positive' or 'reinforcing' feedback are used to describe mechanisms that amplify change, and the terms 'negative' or 'balancing' feedback are used when change is resisted. Feedback effects are important drivers of system response to policy initiatives. For example, negative feedback loops can cause the common phenomenon of 'policy resistance', in which the system 'pushes back' against attempts to change its behavior.

Feedback makes it difficult to design effective policies. A single action can have effects that propagate along multiple causal pathways to produce a wide spectrum of outcomes. The amplifying effect of positive feedback can cause disproportionately large responses to management initiatives. The balancing effect of negative feedback can prevent desired policy outcomes from materializing. Most of these effects will be unexpected, unwanted, and delayed. Because they are delayed their origin will not be understood; there is a strong tendency to blame them incorrectly on some randomly selected, but proximate, cause.

\section{System Dynamics tools}

The discipline of System Dynamics was established by Forrester (1961) specifically to support policy making in complex managed systems. System Dynamics provides practical tools, methods, and ways of seeing that can help people from a wide range of backgrounds to develop better intuitions about the operation of cause and effect in complex systems. The approach offers strong support for the development of cross-sector policy. Meadows (2008) provides an accessible introduction and Sterman (2000) reviews the field thoroughly.

A System Dynamics study involves three coevolving activities:

- Activity 1: gather historical data, time series, and other information to build up the story of the challenge, or problem situation, of concern.

- $\quad$ Activity 2: develop proposed feedback structures for the system of interest and settle on the system boundary that will be adopted in the study.

- Activity 3: build a dynamical model to investigate the behavioral implications of the proposed feedback structure.

In this paper we confine ourselves to a discussion of Activity 2. Even limited efforts to develop plausible feedback structures can broaden policy makers' views of the range of variables that need to be included in their deliberations, and help them to set boundaries for the systems of interest. Furthermore, efforts to identify relevant crosssector feedback loops can nurture productive, focused dialogues between a wider than usual range of players. Such dialogues can help break down the conceptual barriers that hinder the development of systemic policies (Newell et al. 2005). Influence diagrams, causal-loop diagrams, and system archetypes are System Dynamics tools that can support these efforts.

\section{Influence diagrams}

Influence diagrams consist of blocks of text, which describe selected variables of interest, connected by arrows that represent cause and effect links (Fig. 1). This diagram is based on the causal-loop diagrams developed by Proust et al. (2007), discussions by 
Fig. 1. Selected interactions in the climate-electricity-water system. In this influence diagram the blocks of text represent system variables, and the arrows represent cause and effect links. The diagram presents a dynamic hypothesis concerning dominant feedback structures in the system. The variable 'total demand for water' refers to the aggregate water requirements of all sectors including the electricity supply sector. The variable 'total demand for electricity' refers to the aggregate electricity requirements of all sectors, including the water supply sector. The existence of multiple feedback loops raises the possibility that the system will respond in complex, nonlinear ways when perturbed by exogenous and endogenous forces.

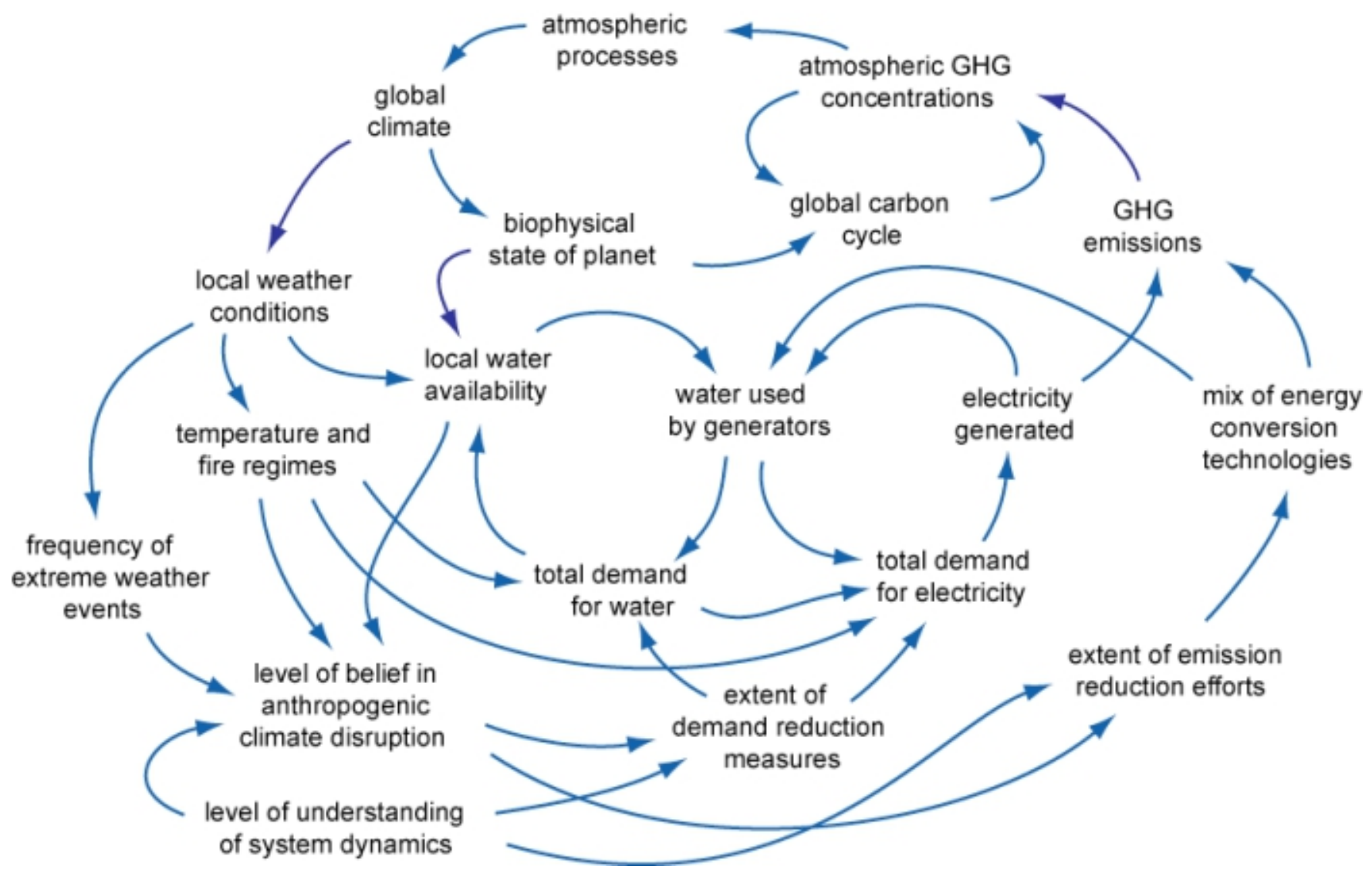

Marsh and Sharma (2007) and Marsh (2008), and the influence diagrams produced by the expert participants in a Climate-Energy-Water Links workshop held at the Australian National University; seven of the latter diagrams are reproduced here in the Appendix.

Figure 1 is designed to highlight the intersection of climate processes, electricity generation, and water supply. The upper feedback structure represents Earth-system interactions that take place on global temporal and spatial scales, whereas the lower structure represents interactions at more regional and local scales. Central to these interactions are the feedback loops that connect electricity generation and water consumption. It is important to recognize that diagrams of this nature are visual representations of tentative dynamic hypotheses; they are not meant to represent the truth. Different individuals, who hold different views of the cause and effect structure of a given system, will produce different influence diagrams. Indeed, the members of a policy design team will not usually define the system of interest in exactly the same way. The value of influence diagrams comes, not from their validity, but from the rich, focused dialogue that their construction and comparison promotes. Such diagrams can become a visual language that allows 
Fig. 2. In this causal-loop diagram, the blocks of text represent system variables and the arrows represent causal links. Each arrow has been assigned a 'polarity' indicated by a plus (+) or minus (-) sign. The encircled $\mathrm{R}$ indicates that this is a reinforcing feedback loop that can cause runaway behavior. The diagram illustrates an example of 'policy resistance', an archetypical feedback structure where the system pushes back against policy pressures.

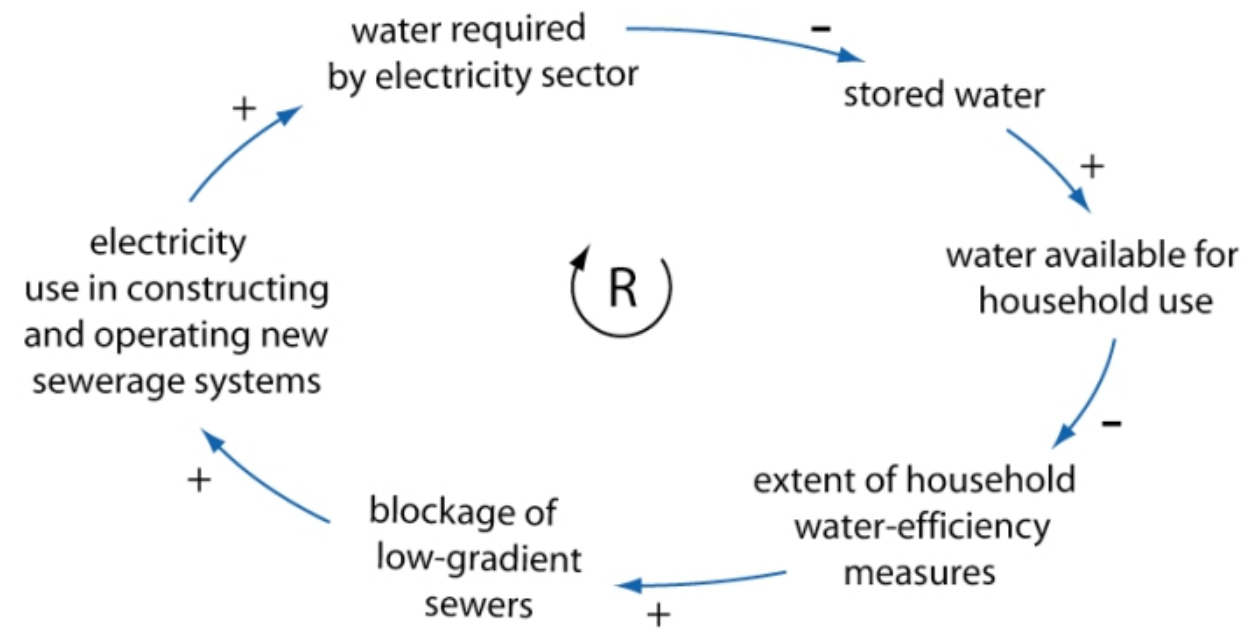

individuals to compare and blend their mental models of the cause and effect structures that underlie a given problem situation or design challenge (Newell and Proust 2009).

\section{Causal-loop diagrams}

Causal-loop diagrams are essentially influence diagrams with each of the cause and effect links assigned a polarity. That is, a plus sign (+) or a minus sign (-) is attached to each arrow. A plus sign means that an increase/decrease in the value of the affecting variable (at the tail of the arrow) will cause the value of the affected variable (at the head of the arrow) to rise above/fall below the value that it otherwise would have had (all else being equal). A minus sign indicates that an increase/decrease in the affecting variable will cause the value of the affected variable to fall below/rise above the value that it otherwise would have had (all else being equal). The addition of these signs allows feedback loops to be classified as either reinforcing or balancing. Such classification can provide insights into the dynamics of hypothesized feedback structures.

The causal-loop diagram shown in Figure 2 illustrates a case of policy resistance. Recent efforts to reduce household water use have caused unexpected problems. Sewers designed assuming high-volume water flows are found to block up when water flows are reduced (Troy 2008). When blockages lead to the installation of electrically driven pressurized sewers, the required increases in electricity demand can lead to increased water use by the electricity sector and so reductions in the water available to households. This is a reinforcing loop that has the potential to undercut efforts to save water. Such effects are not anticipated in the policy design process when the design brief is narrowly defined, and no one has the time or inclination to look for unusual cross-sector feedback loops.

\section{System archetypes}

Research by the System Dynamics community has revealed the existence of system archetypes (Senge 1990). These are relatively simple, generic feedback structures that recur in different guises, and at all scales, throughout social-ecological systems. Members of the Resilience Alliance have also recognized the ability of structures with a small number of state variables to explain the essential behavior of complex systems; they label this observation the 'rule of hand.' According to Walker et al. (2006): 
Fig. 3. Success to the Successful. This archetypical feedback structure is bi-stable, driving the viability and political power of one of the protagonists up while the other's viability and power are driven down. At present the established technologies, as the label indicates, are dominant.

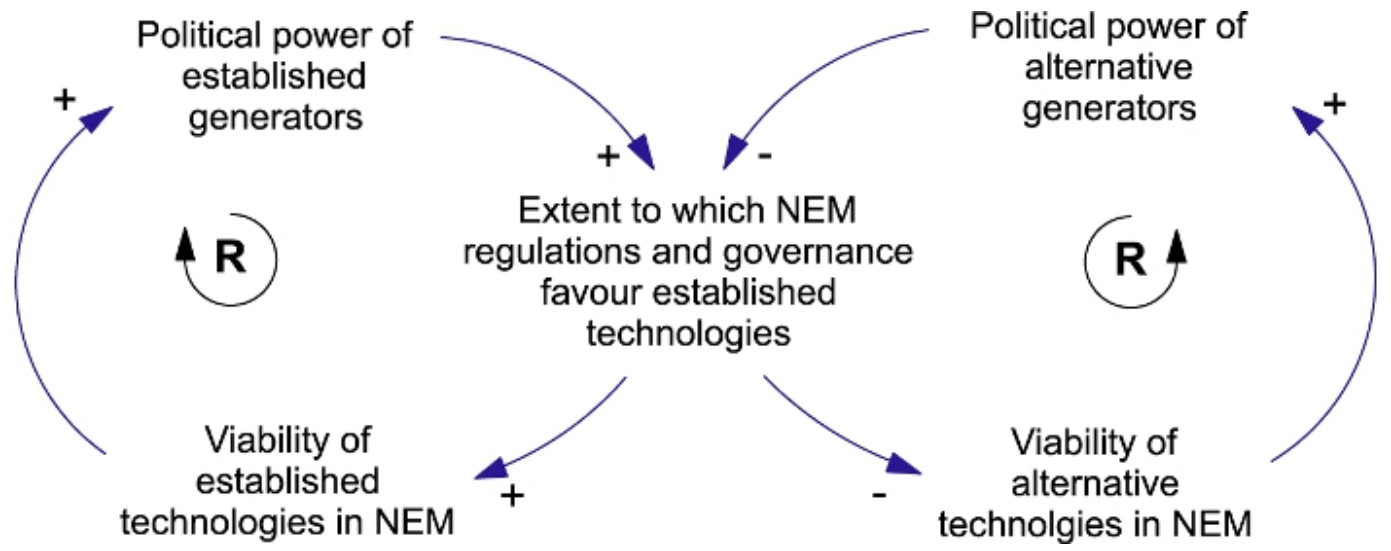

\begin{abstract}
Although social-ecological systems are self-organized through interactions among large numbers of biotic and abiotic variables, the most important changes can be understood by analyzing a few, typically no more than five, key variables... This is the 'rule of hand.' More complex models are not necessary to explain the key interesting patterns and, in fact, are likely to mask them. This is both because generally humans can only understand lowdimensional systems and because, empirically, it appears that only a few variables are ever dominant in observed system dynamics. The essential dynamics of all the case studies in this special issue involved fewer than five key variables at any one scale.
\end{abstract}

System archetypes include the basic feedback structures that drive exponential growth and decay, goal seeking and oscillation, S-shaped growth, overshoot and collapse, and deterministic chaos (Sterman 2000). In addition, there are slightly more complex structures that underlie many common management problems. These structures include, for example, Fixes that Fail, Success to the Successful, Growth and Underinvestment, and Tragedy of the Commons (Senge 1990). Many of them give rise to policy resistance. The causal-loop diagrams presented here in Figures 2 and 3 provide examples. As Meadows (2008) stresses, as long as these archetypical system structures remain hidden they can be management traps. Once recognized, however, they present opportunities for the construction of effective policy interventions. The demonstrated explanatory power of system archetypes makes them essential items in any systems analyst's tool kit (Senge 1990, Sterman 2000).

\section{ENHANCING THE RESILIENCE OF THE AUSTRALIAN NATIONAL ELECTRICITY MARKET}

The Australian National Electricity Market (NEM) is a wholesale generation market that provides electricity to some eight million end-use consumers in Queensland, New South Wales, Victoria, South Australia, Tasmania, and the Australian Capital Territory. It is operated as five interconnected regions, whose boundaries correspond approximately to those of the member states. It is supported by transmission and distribution networks that extend over some 5000 kilometers.

The NEM was established as a result of widespread microeconomic reform of the electricity industries in the member states, from the mid 1990s onward. The reform aimed to improve the economic performance of the industry. Vertically integrated public utilities were separated into generation, transmission, and distribution segments. Competition was introduced in the generation and distribution 
segments, and new regulations allowed third party access to transmission networks.

The NEM is managed by the Australian Energy Market Operator. Every five minutes generators submit bids to supply electricity, and the market operator selects from those bids in an endeavor to meet demand in the most cost-efficient manner. Inter-regional trading is permitted to further encourage competition between generators and help meet stringent reliability standards. The reliability standard specifies that unmet demand must be less than $0.002 \%$ of the total energy consumed per region per year.

The introduction of competition and market mechanisms in the generation segment took place prior to any widespread concern over climate change. The existing market focus favors cheap generation technologies, such as those using coal and gas, which are carbon- and water-intensive. The operation of the NEM is, therefore, vulnerable to changes in climate and energy policies. New policy requirements include a renewable energy target, demand reduction programs, and investment in research into carbon capture and storage. It is also likely that the Australian Federal Government will impose a carbon price in the near future.

The electricity sector recognizes the need to adapt to climate change to increase its resilience. The Australian Energy Market Commission has recently carried out reviews of market frameworks in the light of proposed climate change policies (AEMC 2009), and the effectiveness of NEM security and reliability arrangements in the face of extreme weather events (AEMC 2010). In the wake of the 2007 drought, the energy market operator began to publish drought statements with a 2-year outlook to assess the impact of water shortages on reliability (NEMMCO 2007). This is a critical starting point for the electricity sector, but the discussions also reveal the dominance of narrowly focused economic criteria in the regulatory frameworks. As discussed below, the sector's strong focus on price and economic efficiency acts to reduce the resilience of the NEM.

\section{Resilience of the NEM}

The Resilience Alliance has successfully drawn the attention of the policy making community to resilience as a crucial system property. Resilience can be defined as "the ability of a system to absorb disturbance and still retain its basic function and structure" (Walker and Salt 2006:1).

A resilient electricity supply system would have a number of characteristics that ensure system security and reliability. These characteristics include a governance approach that encourages innovation and diversity, an approach to technology development that recognizes the critical role of modularity and redundancy, and a willingness to take a dynamical systems approach (Walker and Salt 2006). In many respects the NEM, as presently constituted and managed, ranks low on these scales and is therefore vulnerable to the effects of global change. In this section we use causal-loop diagrams to structure a discussion of steps that could reduce this vulnerability. Each of the diagrams represents a dynamic hypothesis that we believe is worth considering in the context of NEM policy design and governance. In this discussion we depend particularly on the analysis carried out by Chin et al. (2008) who, in support of the Garnaut Climate Change Review (Garnaut 2008), have discussed possible NEM market failures and governancerelated barriers to the entry of new technologies.

\section{Encourage innovation and diversity}

Although the NEM is intended to be technology neutral, it has a regulatory and governance structure that makes it difficult for new entrants to compete (Chin et al. 2008). Most of the existing NEM facilities were developed with public funding. In the privatized system new market entrants receive no such subsidies and are unable to compete in price with existing coal-fired power plants. This is particularly true for those businesses wishing to employ alternative technologies (Fig. 3). Furthermore, although new entrants are able to use existing transmission networks, they must fund their own connections to those networks. This can be particularly difficult for companies whose installations are located in remote areas. The possibility of free riding on someone else's network extension exerts a powerful delaying force. It is also difficult for embedded-generation and demandreduction businesses to establish a place in the system. The present regulatory environment, in which network businesses generate their revenue from electricity throughput, makes embedded generation and demand reduction unwelcome prospects for existing operators; such operators have every incentive to resist innovation. Their 
Fig. 4. NEM resilience. This diagram depicts a balancing feedback loop that, if activated, can drive NEM resilience up to new levels when security and reliability of supply are threatened. We suggest that the NEM control system needs to include such a feedback structure.
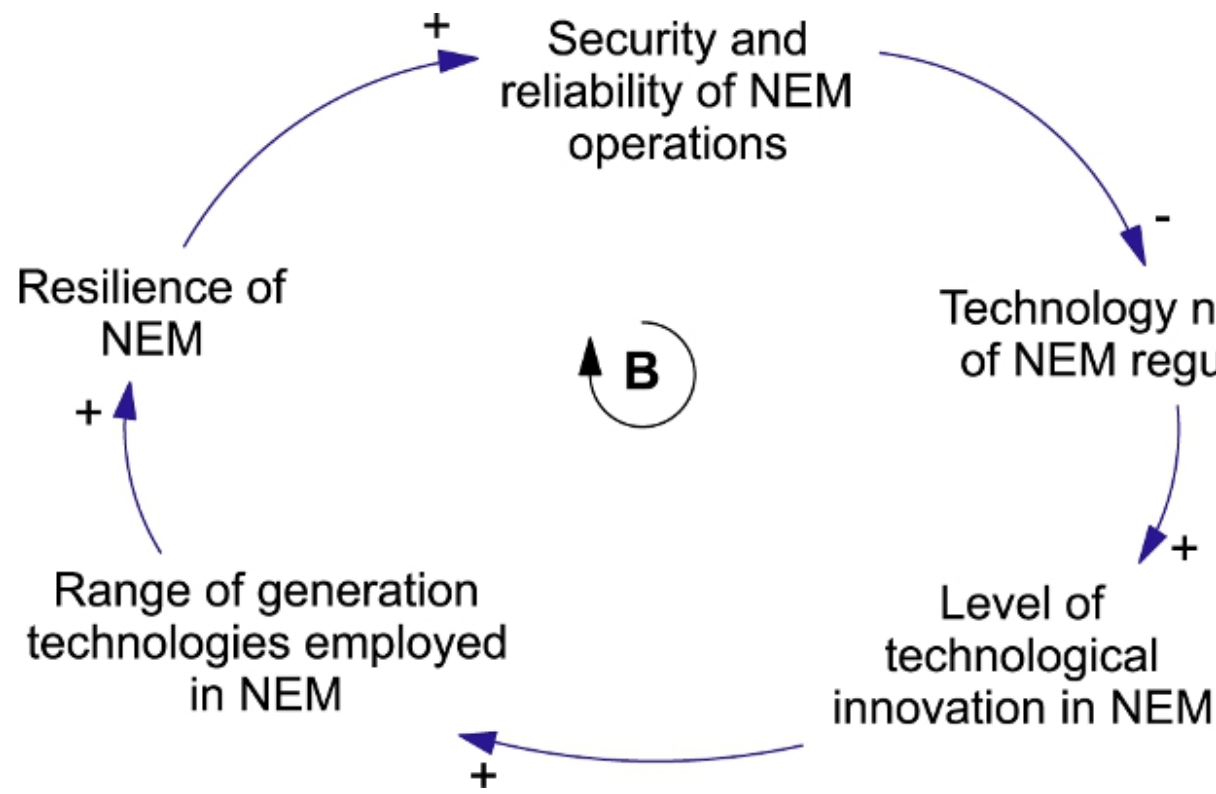

ability to do this is enhanced by their control of information about their networks.

In the causal-loop diagram of Figure 4 we outline a dynamic hypothesis concerning a possible NEM resilience control loop. The structure depicted is a balancing feedback loop that, in the absence of perturbations, will settle into a stable state. As long as supply is seen to be secure and reliable, there will be little incentive to alter the values of the other variables around the loop. If, however, changing conditions lead to an increasing number of security and reliability failures, and if the lack of technology neutrality is recognized, there will be pressure to increase neutrality by overcoming some of the barriers to innovation and diversity. Such actions would boost innovation, increase the range of technologies employed, and so increase resilience. Increased resilience would then increase NEM security and reliability. Development of a feedback mechanism of this type could help the NEM to track changing conditions.

The hypothetical resilience control loop depicted in Figure 4 works only if the importance of technology neutrality is recognized. The NEM, as now organized, uses increasing spot-price volatility as a signal that system capacity is inadequate. Currently, the main response to such price signals is to increase the number of coal- and gas-fired power stations. This response, of course, increases electricity supply without increasing the resilience of the NEM. A crucial step, toward an electricity supply system that can evolve to meet changing conditions, is to increase technology neutrality. Possible strategies include government subsidies for alternative technologies, a carbon price to reduce the monopoly of fossil fuel-based generation, regulations that reward network operators for the provision of services rather than energy throughput, and improved access to distribution-network information.

\section{Support modularity and redundancy}

The ability of a complex social-ecological system to adapt to change depends in part on the level of redundancy in its infrastructure and governance arrangements (Walker and Salt 2006). Within the NEM there is a dominant focus on operational and 
Fig. 5. The tension between a reliance on market mechanisms and the need to take a systems approach. This is a reinforcing feedback loop that tends to drive governance approaches to one extreme or the other.

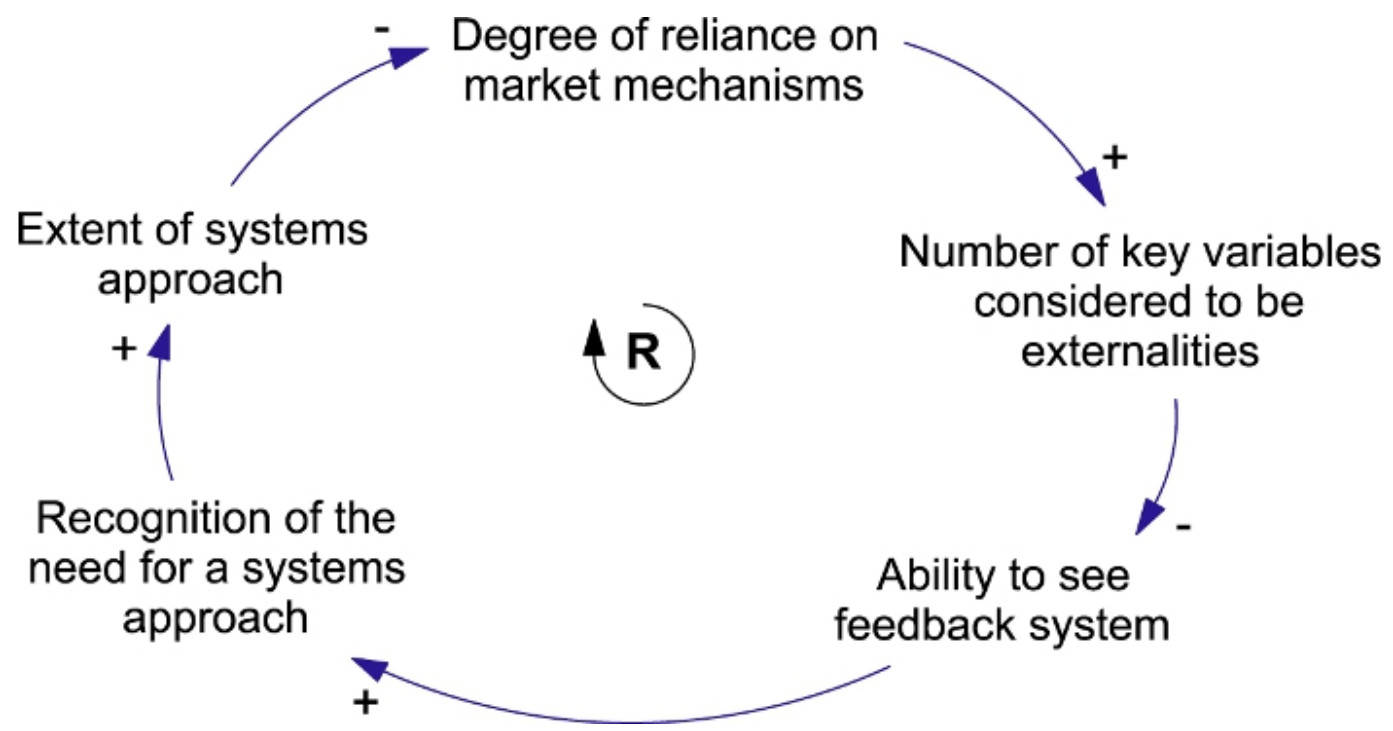

economic efficiency that works to reduce redundancy. The result is a strongly connected system with top-down control. Although the NEM provides a certain level of redundancy by allowing inter-region transmission, and establishing minimumcapacity reserve levels to meet the reliability standard, the transmission lines that connect regions are vulnerable to temperature changes that reduce their reliability and capacity at precisely those times when loads are maximum.

The resilience of the NEM could be enhanced by building additional redundancy into the transmission and distribution networks. The expenditure required to build alternative transmission links is sometimes justified, in specific locations, on the basis of increasing energy security in the face of wild fires. However, given the distances and costs involved, this is not a common solution. A much cheaper option, in the long run, would be to encourage distributed generation, even to the extent that individual residences and businesses acquire some capability to generate their own power. For example, the use of rooftop photo-voltaic systems is rapidly becoming more cost-effective. As battery technology continues to develop it is also possible to envision households and business that have complete electrical autonomy. The gains in electricity security and reliability would be significant.

The creation of a national energy market, with a large number of interconnected power stations, may seem to increase reliability by increasing redundancy. If one generator should fail, others can pick up the load. However, it is important to realize that the opposite may be true, particularly when the supply-demand balance is tight. A systems approach, with a focus on resilience, raises the notion that a more modular arrangement might be much less vulnerable to disruption. This is an issue that requires investigation.

Embrace the need for a dynamical systems approach

In Figure 5 we present a feedback loop that captures our hypothesis that, in NEM design and governance, there is a natural tension between a reliance on market mechanisms and the need for a broad systems approach. This reinforcing feedback loop is bistable. That is, all else being equal, the state of the system will tend to lock-in at one extreme or the other, either a strong dependence on market mechanisms, with many key variables regarded as externalities, or a strong systems approach with 
Fig. 6. The electrification of transport. This diagram depicts a reinforcing feedback loop that has the potential to cause policy resistance.

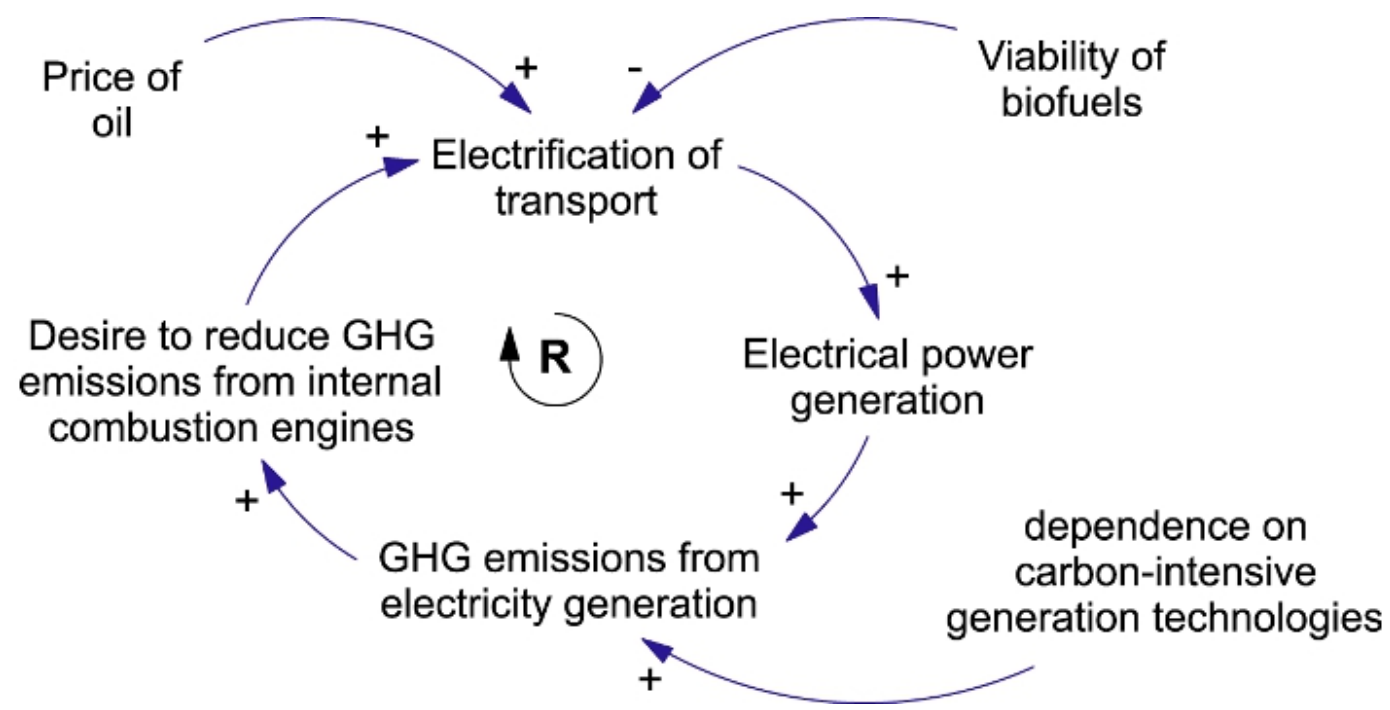

those same variables seen as internal to the system. Market mechanisms dominate at present. Recognition of this tension is an essential first step toward the establishment of a wider view of the factors that influence NEM resilience in the longer term.

It is difficult to include the full costs to society in the design and governance of an electricity market. This is particularly true in the case of the NEM where there is such a heavy reliance on fossil fuels. As emphasized by Chin et al. (2008:14) the NEM is prone to market failure in this context:

[A market failure is deemed to occur] when a market fails to provide goods and services in an economically optimal manner ... market failure occurs when society's marginal costs do not equate to the marginal benefits to society for a particular good or service. As a result, market price signals do not reflect the full social costs of producing the good or service and so producers under or over produce the good from a societal perspective.

In these circumstances it is necessary to supplement market considerations with a systems view to properly assess the potential long-term impact of NEM operations on the wider social-ecological system. This wider view must encompass a range of spatial, temporal, and social scales, and the insights gained must be given high weight in the process of NEM strategic planning. At issue here is the challenge of ensuring that the full socialecological system, including the NEM, evolves toward higher resilience as time passes.

\section{Feedback dynamics of the wider social- ecological system}

The construction of influence diagrams like that displayed in Figure 1 and those shown in the Appendix, can help an NEM policy making team to isolate potentially important feedback loops that close through a range of sectors. A subsequent investigation of the dynamical implications of those structures can help the team to move toward a better understanding of the interactions between the NEM and the wider social-ecological system. A practical first step in such an investigation is to construct causal-loop diagrams of the candidate feedback loops. Figures 6, 7, and 8 illustrate the kind of diagrams that are required.

\section{Policy resistance}

The reinforcing feedback loop depicted in Figure 6 provides an example of possible policy resistance 
Fig. 7. An example of policy resistance that can reduce the effectiveness of carbon capture and storage (CCS) initiatives.

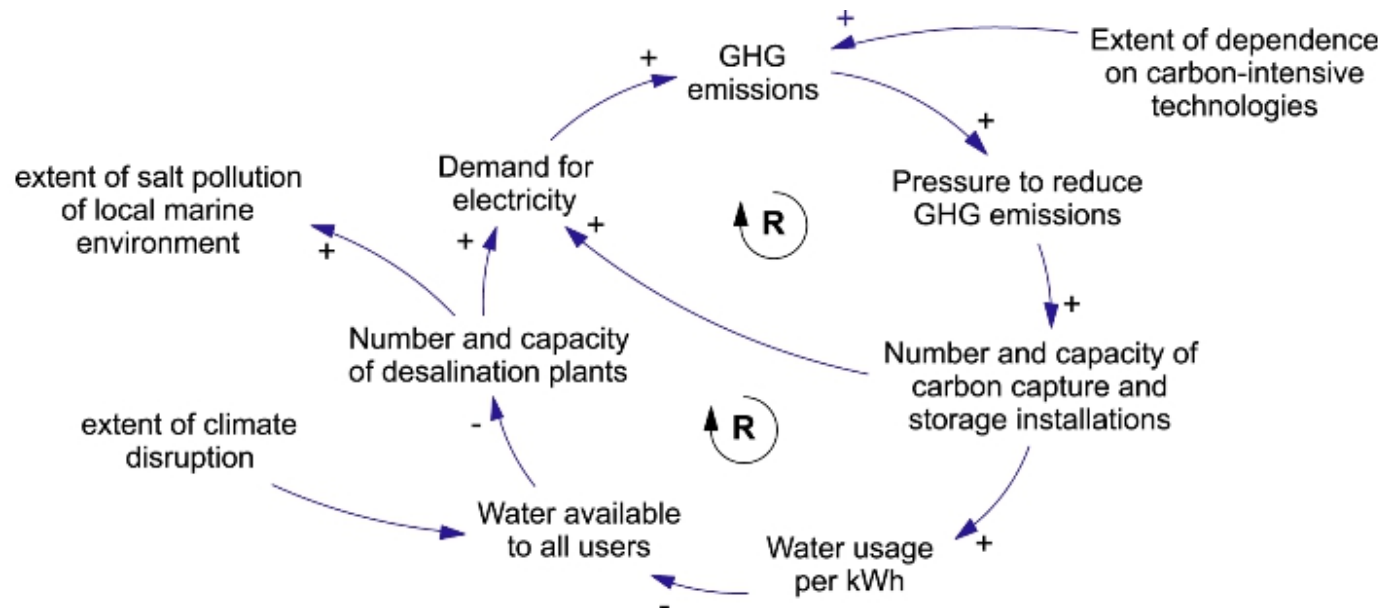

in the NEM. Transport electrification is a sensible way to reduce $\mathrm{GHG}$ emissions from internal combustion engines. However, as long as the required electricity is generated using carbonintensive technologies, the electrification will result in additional GHG emissions from power generation. This increase will undercut the gains made from transport electrification. Also shown in Figure 6 are two variables, 'price of oil' and 'viability of biofuels,' that have the potential to affect the extent of transport electrification. An increase in oil prices will tend to increase pressure for electrification, whereas an increase in the viability of biofuels will tend to reduce pressure for electrification. In the latter case, there will be lower level of additional emissions from power generation, but also a smaller reduction of vehicular GHG emissions. The inclusion of the variable 'viability of biofuels' also points to the wider connections between the NEM, the agricultural sector, and the water supply sector. Obviously, the electrification strategy will work only if it results in a significant net reduction in GHG emissions from all of the sectors affected.

Another example of a feedback structure than can contribute to policy resistance is shown in Figure 7. This structure comprises two reinforcing feedback loops that have the potential to reduce the effectiveness of carbon capture and storage installations (CCS). CCS installations require both water and electricity. For the same net power output, CCS consumes potentially double the amount of water per net MWh generated, compared with current practice coal-fired technology, because of the increase in auxiliary power requirements and the additional cooling water consumed in the carboncapture process (King et al. 2008). If the required water is supplied by desalination plants, then even more electricity will be required and there will be a potential for pollution of the marine environment. CCS is expected to significantly increase the cost of electricity, which will increase the operation costs for those water utilities that become more energyintensive under climate change adaptation policies. Similarly, dry-cooling technology reduces generation efficiency because more power is required to run the plant (Electric Power Research Institute 2002). The technology therefore increases carbon emissions from a plant, thereby undercutting climate adaptation efforts.

\section{Electricity-water interactions}

It is not possible to optimize the resilience of the NEM, or water supply utilities, in isolation from each other, or from consideration of long-term climate trends. Many large-scale electricitygeneration processes consume water, and most bulk water supply processes require the expenditure of significant amounts of electricity (Ghassemi and White 2007). Climate affects the demand for electricity and water, and conventional energy conversion processes have the potential to contribute to climate change. 
Fig. 8. The electricity-water nexus. This diagram illustrates the Tragedy of the Commons system archetype as applied to the competition for water between the electricity sector and other sectors that use water. Overuse of this resource leaves all users vulnerable to the effects of climate change.

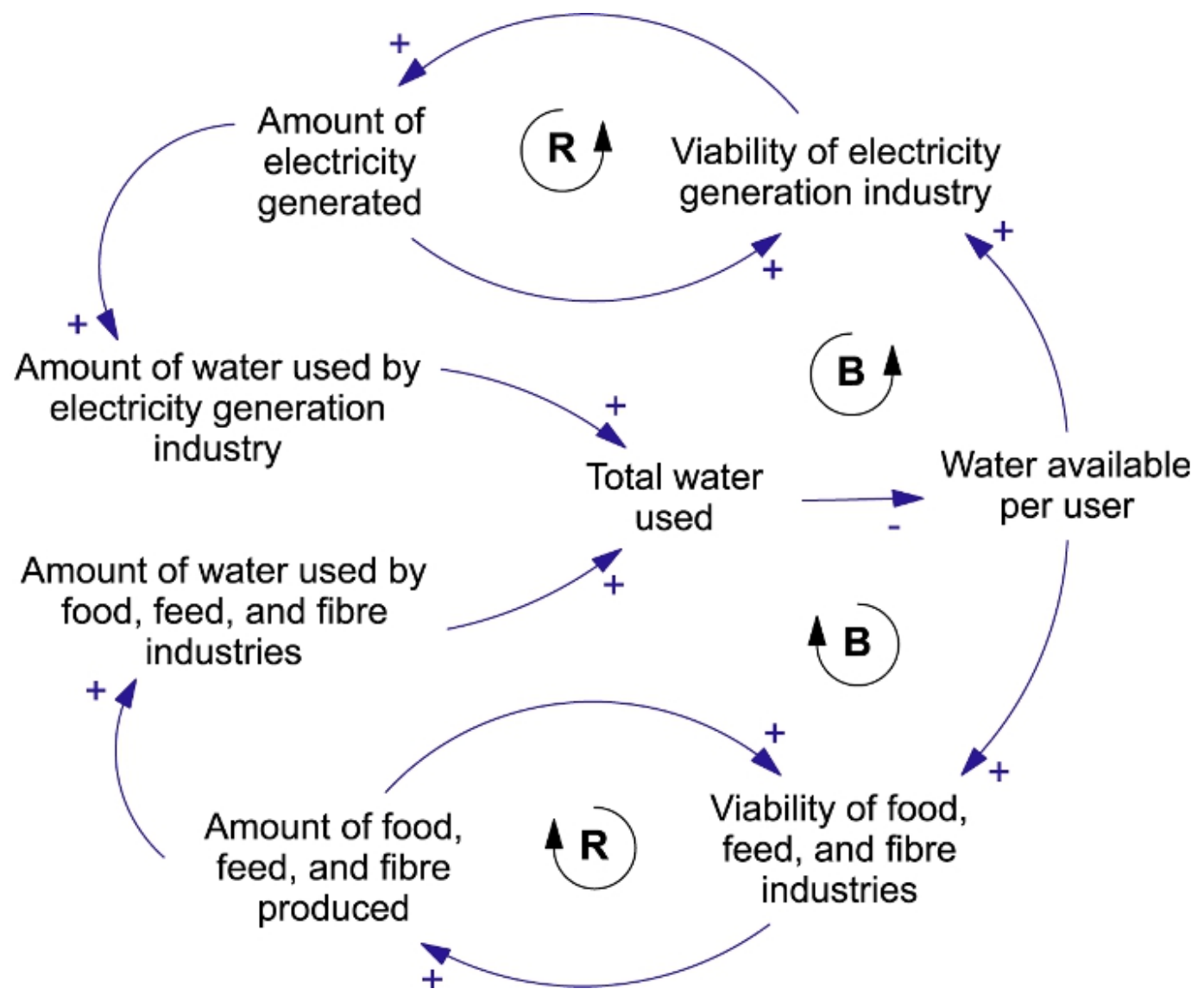

In the southern parts of Australia, there is a significant risk of a tragedy of the water commons unless the electricity and water sectors work closely together. In his original Tragedy of the Commons paper, Hardin (1968) discusses the possible collapse of social systems in which many uncoordinated individuals overuse a scarce resource. As the resource shrinks, each individual has to work harder and harder to extract an adequate amount of the resource. Each person receives direct benefit from the amount that he or she extracts, but carries only a share of the delayed costs of overexploitation. The long-term effect, in the absence of integrative policy, is to cause the resource to collapse, taking the social system with it.

In Figure 8 we display the tragedy of the commons system archetype (Senge 1990) as applied to the electricity-water nexus. An increase in the total amount of water used reduces the water available per user thus making all users more vulnerable to disruptions of the water supply. Recent events in Australia suggest that such considerations are relevant to NEM policy discussions. In May 2007 severe lack of water curtailed generation capacity in the NEM, resulting in a threefold increase in the wholesale price (Bildstein 2007). Generators purchased emergency water from nearby coal mines and regional water markets. They used river water that was normally extracted only during periods of high river flows, and transferred output from inland to coastal power plants. Also, in reaction to historically low levels in water storage dams, the industry began to invest in less water-intensive gasfired power generation as a contingency measure against losses in hydropower generation capacity 
(Kleinman and Houston 2007, New South Wales Government 2007, Wilkinson and Smith 2007). The electricity sector's response to a lack of water had impacts on other water users. Australian generators sourced cooling water from drinking water supplies, despite the existence of regional water-use restrictions and sufficient generation capacity elsewhere in the NEM (Roberts 2007). The National Generators Forum, Australia's peak representative body for electricity generators, also stated that governments should consider lifting environmental constraints on generators, by reducing environmental flow allocations, if there is insufficient water for electricity generation in the future (Cowan 2007). These problems persist in southeastern Australia, being reported most recently in Oberon, New South Wales, where falling water levels led to conflict between the Shire Council and the nearby Wallerawang power station (Cubby and Wilkinson 2009).

Narrowly focused policies can exacerbate the situation, especially if they generate policy resistance. This can happen, for example, with the installation of energy-intensive advanced wastewater treatment plants, desalination plants, and rainwater tanks. Such facilities increase the energy intensity of water supply, increase the amount of water used in power generation, and thus undercut watersaving efforts (Marsh 2008). Similarly, climate change mitigation policies can have the unintended consequence of increasing water consumption. The case of CCS has been discussed above (Fig. 7). Geothermal plants also will reduce carbon emissions from the electricity sector, but require water to generate steam. Even closed-loop geothermal technologies, because they suffer water losses, may create regional water conflicts in inland drought-prone areas where high quality geothermal resources are located (Marsh 2008). A mediumterm shift from coal- to gas-fired electricity generation is likely with the introduction of a carbon price, because gas is less carbon-intensive (ACIL Tasman 2008, McLennan Magasanik Associates 2008, ROAM Consulting 2008). Conflicts may arise if future gas-fired plants are allowed to draw on local potable-water supplies, particularly if water-use restrictions are in place. In addition, a shift from coal to gas will increase incentives to use coal-seam gas. Coal-seam gas reserves require rewatering from local water sources, once the gas has been extracted, so that coal mining may commence (S. Vink, personal communication). This can create conflict in areas already experiencing water shortages. Nevertheless, Ostrom (1990) counsels that such situations are not necessarily subject to "a remorseless tragedy." Lack of water is a very obvious threat to electricity security in Australia. Bringing this threat to the forefront of thinking in the electricity sector will increase the chances of it being accounted for in NEM policies. It should be possible to establish cross-sector water-use policies that at least minimize conflict. The water-gathering behaviors displayed during recent droughts send a clear signal to the electricity sector that the urgent development of such integrated policies would be wise.

\section{Next steps}

We have argued that the resilience of the NEM can be enhanced if its infrastructure and regulatory framework take account of a greater range of variables than is usually the case in a market-based operation. Influence diagrams and causal-loop diagrams can support initial efforts to develop policies that take account of the wider socialecological system. The activity of constructing such diagrams can help policy makers to identify critical variables, clarify system-of-interest boundaries, trace dominant feedback structures, and propose feedback links to make or break. A search for system archetypes can help in this endeavor.

Nevertheless, although such tools can help a policy making team to expand their understanding of the factors that must be taken into account to avoid unwelcome surprises, they are not enough. Detailed explorations of policy impacts, and the generation of rich outcome scenarios, require the construction of working dynamical models (Sterman 2000). The primary aim of such a modeling program (listed as Activity 3, above) must not be to model whole social-ecological systems, but to isolate relatively simple stock-and-flow structures that have the potential to dominate the behavior of systems of interest. This can be done by building moderately complex models and then using sensitivity and stability analyses to isolate the dominant structures. An attempt to build working models also helps to reveal knowledge gaps and drives data-gathering efforts. There is an extensive literature regarding the use of such models in the development and testing of policy (Sterman 2000). Group model building provides an effective way to blend the worldviews of a wide range of players and to ensure their engagement with the insights generated during the modeling process (Holling 1978, Vennix 1996). 


\section{RECOMMENDATIONS}

Policy making in complex social-ecological systems will always require a range of frameworks, including dialogic approaches (Habermas 1985, Roberts 2002), evidence-based policy making (Pawson 2006), and incrementalism (Lindblom and Woodhouse 1993). In these approaches the main emphasis tends to be placed on how information can be used to generate policy choices, and how various interests can be reconciled to produce consensus. What is missing from most policy discussions, however, is a concerted effort to understand the dynamics of the system of interest. Without that understanding it is unlikely that the resultant policies will promote social and ecological resilience in a changing world.

The NEM case study provides several general insights into the challenge of building systemic policy. These insights are summarized here in the form of recommendations. Our aim is to suggest actions that are necessary in attempts to develop policies that are effective and sustainable in complex situations. All three recommendations will take time to implement and have significant effects. From our point of view this is not a reason to reject them; it is a reason to get started as soon as possible.

\section{Recommendation 1}

Do not rely entirely on market mechanisms. Although market forces can be relied on in many circumstances, there is a limit to their effectiveness in complex systems. Many of the variables that are seen as externalities when looked at from a market perspective are internal to social-ecological systems. There is a need to balance market approaches with systems approaches.

We believe that there is a natural tension between current market approaches and systems approaches (Fig. 5). From a systems point of view, an exclusive focus on markets restricts the policy maker's view to narrowly defined subsystems. However, as stated above, the behavior of a system cannot be optimized by attempting to optimize the behavior of its subsystems taken in isolation from one another. This means that policies that are based on market considerations alone are likely to produce unexpected and unwanted outcomes. Systems concepts and analysis tools, like those developed by the Resilience Alliance and the System Dynamics community, can help policy makers assess the limits of market mechanisms and devise ways to blend market insights into the wider social-ecological picture.

\section{Recommendation 2}

Establish intense and continuing dialogue across a wide range of sectors. No one person or group can see the whole system (Churchman 1968). Conceptual integration is a necessary step toward a systems approach. Such integration depends on the prior development of a shared conceptual framework, which cannot be done without a significant investment of time and energy (Newell et al. 2005). The time pressures imposed on modern research and policy making communities leads them to place little reliance on dialogue. This stance is self-defeating. Progress toward social-ecological resilience will be more rapid if policy makers first slow down and take advantage of the diversity of thinking that exists around key issues. There is much to be gained from serious efforts to blend disparate worldviews to produce new, emergent understandings.

\section{Recommendation 3}

Promote basic education in system dynamics. Anyone who has worked with managers and policy makers in efforts to take a systems approach rapidly becomes aware of a significant educational burden. Even though unified conceptual frameworks and practical analytic tools have been available for some 40 years, they are relatively unknown and unused. The fundamentally important concept of feedback, for example, has been prominent in engineering and science, including social science, for over 50 years and yet rarely appears in school or university curricula (Richardson 1991), the most obvious exception being courses in feedback control and robotics as taught in university engineering departments. The development of a much wider appreciation of the need for dynamical thinking in policy design remains an overarching educational challenge (Sterman 2008, 2010, Rockström et al. 2009).

The current widespread lack of knowledge of basic system principles and system analysis tools perpetuates the implementation of policies based on inadequate mental models. In the worst cases these underlying models can "violate fundamental 
physical principles" (Sterman 2008:533). No matter what policy making approach is adopted, one thing remains constant: the long-term effectiveness of a policy depends critically on how its designers think the managed system works. Those policy makers and managers whose mental models of cause and effect incorporate accumulation and feedback processes, will recognize the unreliability of linear thinking, and are likely to support efforts to increase our overall understanding of the dynamics at play in social-ecological systems. Such intuitions are necessary to guide the policy making community through the formidable institutional and conceptual barriers that stand in the way of anyone who seriously tries to take a systems approach (Newell et al. 2005).

\section{CONCLUSION}

Dynamical concepts such as accumulation, feedback, and resilience, and the collaborative use of influence diagrams, causal-loop diagrams, and system archetypes to map out possible feedback structures, are essential elements of a practical systems approach. Our case study of the Australian National Electricity Market demonstrates how such concepts and analysis tools can be used to initiate the development of systemic policies. We use the case study to explain how the electricity sector can protect itself against the effects of global changeby encouraging innovation and diversity, supporting modularity and redundancy, and embracing the need for policies that look beyond market mechanisms to take account of the dynamics of the wider social-ecological system. Finally, taking a longer term view of what it means to take a systems approach, we recommend that policy makers work to reduce reliance on conventional market mechanisms, institute continuing crosssector dialogue, and promote basic education in system dynamics.

It is difficult and time consuming to develop policies that take account of the dynamics of socialecological systems. However, in many cases, policy making is so fragmented that even modest steps toward a systems approach can represent significant advances. Furthermore, systems science has now advanced to the point where it can provide solid theoretical and practical support to such efforts. At one end of the scale, the collaborative construction of simple influence diagrams can help policy makers to see and discuss possible cross-sector feedback loops that need to be taken into account. The process can also reveal potential sources of delay, policy inertia, and policy resistance. At the other end of the scale, dynamical modeling offers the possibility of investigating the relative effectiveness of competing policies, and thus mapping out plausible future-development scenarios. The overarching goals must remain the development of good scientific methods, the construction and testing of usefully simple dynamic hypotheses, and the establishment of cross-sector collaborations whose participants communicate well and learn from each other.

Responses to this article can be read online at: http://www.ecologyandsociety.org/voll6/iss2/art15/ responses/

\section{Acknowledgments:}

This work is a part of a joint ANU-UTS ClimateEnergy-Water Links Project, which was funded by The Australian National University, through the Hilda John Water Endowment Fund, and the University of Technology, Sydney. We thank Amy Hardberger, Karen Hussey, Carey King, and Katrina Proust for useful discussions and comments on earlier drafts. Several reviewers have helped with critical comments.

\section{LITERATURE CITED}

ACIL Tasman. 2008. Impacts of the carbon pollution reduction scheme and RET: modelling of impacts on generator profitability. Department of Climate Change, Canberra, Australian Capital Territory, Australia.

Australian Energy Market Commission (AEMC). 2009. Review of energy market frameworks in light of climate change policies: final report. AEMC, Sydney, New South Wales, Australia. [online] URL: http://www.aemc.gov.au/Media/docs/Review\% 20Final\%20Report-9f02959f-0446-48ba-89a1-588 2d58e11fd-0.PDF.

Australian Energy Market Commission (AEMC). 2010. AEMC review of the effectiveness of NEM security and reliability arrangements in light of 
extreme weather events. Consultation Paper. AEMC, Sydney, New South Wales, Australia. [online] URL: http://www.aemc.gov.au/Media/docs/ Final\%20Report\%20no\%20appendicesc35402b0-06dd-4aaf-9033-15b67a441bd0-0.pdf.

Axelrod, R. M., and M. D. Cohen. 1999. Harnessing complexity: organizational implications of $a$ scientificfrontier. Free Press, New York, New York, USA.

Bettencourt, L., and G. West. 2010. A unified theory of urban living. Nature 467:912-913.

Bildstien, C. 2007. Power price rise alarms industry. The Advertiser, 14 May, Adelaide, South Australia, Australia.

Boyden, S., S. Millar, K. Newcombe, and B. O'Neill. 1981. The ecology of a city and its people: the case of Hong Kong. Australian National University Press, Canberra, Australian Capital Territory, Australia.

Chin, L., R. Gawler, and W. Gerardi. 2008. NEM market failures and governance barriers for new technologies. Final report to Garnaut climate change review. McLennan Magasanik Associates, Melbourne, Victoria, Australia. [online] URL: http ://www.garnautreview.org.au/CA25734E0016A131/ WebObj/NationalElectricityMarketFailuresandGov ernanceBarriersforNewTechnologies/\$File/National\% 20Electricity\%20Market\%20Failures \%20and\% 20Governance\%20Barriers\%20for\%20New\% 20Technologies.pdf.

Churchman, C. W. 1968. The systems approach. Dell, New York, New York, USA.

Cowan, J. 2007. Water shortages worry power stations. PM Program, ABC Radio, 10 May, Australia.

Cronin, M. A., C. Gonzalez, and J. D. Sterman. 2009. Why don't well educated adults understand accumulation? A challenge for researchers, educators, and citizens. Organizational Behaviour and Human Decision Processes 108:116-130.

Cubby, B., and M. Wilkinson. 2009. People v power station as water levels plunge, Sydney Morning Herald, 19 November, Sydney, New South Wales, Australia.
Electric Power Research Institute. 2002. Comparison of alternate cooling technologies for California power plants: economic, environmental and other tradeoffs. California Energy Commission, Sacramento, California, USA.

Forrester, J. W. 1961. Industrial dynamics. Productivity Press, Portland, Oregon, USA.

Garnaut, R. 2008. The Garnaut climate change review: final report. Cambridge University Press, Cambridge, UK.

Ghassemi, F., and I. White. 2007. Inter-basin water transfer: case studies from Australia, United States, Canada, China and India. International Hydrology Series. Cambridge University Press, Cambridge, UK.

Gunderson, L. H., and L. Pritchard, Jr., editors. 2002. Resilience and the behaviour of large-scale systems. Island Press, Washington, D.C., USA.

Habermas, J. 1985. The theory of communicative action. Beacon Press, Boston, Massachusetts, USA.

Hansen, J., M. Sato, P. Kharecha, D. Beerling, R. Berner, V. Masson-Delmotte, M. Pagani, M. Raymo, and D. L. Royer. 2008. Target atmospheric $\mathrm{CO}_{2}$ : where should humanity aim? Open Atmospheric Science Journal 2:217-231.

Hardin, G. 1968. The tragedy of the commons. Science 162:1243-8.

Holling, C. S., editor. 1978. Adaptive environmental assessment and management. Wiley, Chichester, UK.

Intergovernmental Panel on Climate Change (IPCC). 2004. 16 years of scientific assessment in support of the climate convention. Intergovernmental Panel on Climate Change, Geneva, Switzerland. [online] URL: http://www.ipcc.ch/pdf/10th-anniversary/ anniversary-brochure.pdf.

International Council for Science (ICSU). 2010. Grand challenges in global sustainability research: a systems approach to research priorities for the decade. International Council for Science, Paris, France.

King, C., I. Duncan, and M. Webber. 2008. Water demand projections for power generation in Texas. 
Bureau of Economic Geology, University of Texas at Austin, Austin, Texas, USA.

Kleinman, R., and C. Houston. 2007. Drought puts pressure on state's power supply. The Age, 10 May, Melbourne, Victoria, Australia.

Lindblom, C. E., and E. J. Woodhouse. 1993. The policy-making process. Prentice Hall, Englewood Cliffs, New Jersey, USA.

Marsh, D. 2008. The water-energy nexus: a comprehensive analysis in the context of New South Wales. Dissertation. University of Technology, Sydney, New South Wales, Australia. [online] URL: http://utsescholarship.lib.uts.edu.au/dspace/ handle/2100/1075.

Marsh, D., and D. Sharma. 2007. Energy-water nexus: an integrated modelling approach. International Energy Journal 8:235-242.

McLennan Magasanik Associates. 2008. Impacts of the carbon pollution reduction scheme on generator profitability. Department of Climate Change, Canberra, Australian Capital Territory, Australia.

Meadows, D. 2008. Thinking in systems: a primer. Chelsea Green, White River Junction, Vermont, USA.

Mitchell, M. 2009. Complexity: a guided tour. Oxford University Press, New York, New York, USA.

National Electricity Market Management Company (NEMMCO). 2007. Potential drought impact on electricity supplies in the NEM: final report. NEMMCO, Sydney, New South Wales, Australia.

Newell, B., C. L. Crumley, N. Hassan, E. F. Lambin, C. Pahl-Wostl, A. Underdal, and R. Wasson. 2005. A conceptual template for integrative humanenvironment research. Global Environmental Change Part A 15(4):200-307.

Newell, B., and K. Proust. 2009. I see how you think: using influence diagrams to support dialogue. ANU Centre for Dialogue, Canberra, Australian Capital Territory, Australia. [online] URL: http://www.anu. edu.au/dialogue/2009/I\%20See\%20How\%20You\% 20Think.pdf.

New South Wales Government. 2007. Owen inquiry, background paper 1 - future of electricity generation in NSW. NSW Department of Premier and Cabinet, Sydney, New South Wales, Australia. [online] URL: http://www.dpc.nsw.gov.au/ data/a ssets/pdf file/0004/13783/BackgroundPaper1.pdf

Ostrom, E. 1990. Governing the commons: the evolution of institutions for collective action. Cambridge University Press, Cambridge, UK.

Pawson, R. 2006. Evidence-based policy: a realist perspective. Sage, London, UK.

Prime Minister's Science Engineering and Innovation Council (PMSEIC). 2010. Challenges at energy-water-carbon interfaces. Report of the Expert Working Group, Prime Minister's Science Engineering and Innovation Council, Canberra, Australian Capital Territory, Australia. [online] URL: http://www.chiefscientist.gov.au/wp-content/ uploads/FINAL_EnergyWaterCarbon_for_WEB.pdf

Proust, K., S. Dovers, B. Foran, B. Newell, W. Steffen, and P. Troy. 2007. Climate, energy and water: accounting for the links. Discussion Paper, Land \& Water Australia, Canberra, Australian Capital Territory, Australia. [online] URL: http://w ww.crdc.com.au/uploaded/File/E-Library/E-ENVIRO/ Climate Energy and Water May 2007.pdf.

Richardson, G. P. 1991. Feedback thought in social science and systems theory. Pegasus Communications, Waltham, Massachusetts, USA.

ROAM Consulting. 2008. Modelling of carbon pricing scenarios. Department of Climate Change, Canberra, Australian Capital Territory, Australia.

Roberts, G. 2007. Blackouts on way as power plants dry up. The Australian, 9 March, Australia.

Roberts, N. C., editor. 2002. The transformative power of a dialogue. Elsevier, Oxford, UK.

Rockström J., W. Steffen, K. Noone, A. Persson, F. S. Chapin, E. F. Lambin, T. M. Lenton, M. Scheffer, C. Folke, H. J. Schellnhuber, B. Nykvist, C. A. de Wit, T. Hughes, S. van der Leeuw, H. Rodhe, S. Sörlin, P. K. Snyder, R. Costanza, U. Svedin, M. Falkenmark, L. Karlberg, R. W. Corell, V. J. Fabry, J. Hansen, B. Walker, D. Liverman, K. Richardson, P. Crutzen, and J. A. Foley. 2009. A safe operating space for humanity. Nature 461:472-475. 
Scheffer, M. 2009. Critical transitions in nature and society. Princeton University Press, Princeton, New Jersey, USA.

Senge, P. M. 1990. The fifth discipline: the art \& practice of the learning organization. Random House, Sydney, New South Wales, Australia.

Steffen, W. 2009. Climate change 2009: faster change \& more serious risks. Department of Climate Change, Australian Government, Canberra, Australian Capital Territory, Australia.

Steffen, W., A. Sanderson, P. D. Tyson, J. Jäger, P. A. Matson, B. Moore, F. Oldfiled, K. Richardson, H. J. Schnellnhuber, B. L. Turner, and R. J. Wasson. 2004. Global change and the Earth system: a planet under pressure. Springer, Berlin, Germany.

Sterman, J. D. 2000. Business dynamics: systems thinking and modeling for a complex world. Irwin/ McGraw-Hill, Boston, Massachusetts, USA.

Sterman, J. D. 2008. Risk communication on climate: mental models and mass balance. Science 322:532-533.

Sterman, J. D. 2010. Does formal system dynamics training improve people's understanding of accumulation? System Dynamics Review 26:316-334.

Troy, P. 2008. A new solution. Page 203 in P. Troy, editor. Troubled waters: confronting the water crisis in Australia's cities. ANU E Press, Canberra, Australian Capital Territory, Australia.

Vennix, J. A. M. 1996. Group model building: facilitating team learning using system dynamics. Wiley, Chichester, UK.

Walker, B. H., L. H. Gunderson, A. P. Kinzig, C. Folke, S. R. Carpenter, and L. Schultz. 2006. A handful of heuristics and some propositions for understanding resilience in social-ecological systems. Ecology and Society 11(1): 13. [online] URL: http://www.ecologyandsociety.org/vol11/iss1/ art13/.

Walker, B., and D. Salt. 2006. Resilience thinking: sustaining ecosystems and people in a changing world. Island Press, Washington, D.C., USA.
Wilkinson, M., and A. Smith. 2007. Drought will force power costs up: ministers. The Sydney Morning Herald, 26 May, Sydney, New South Wales, Australia. 


\section{APPENDIX 1 \\ Influence diagrams from the ANU Climate-Energy-Water Links Workshop}

Newell and Proust (2009) have developed an efficient 'pair-blending' process where influence diagrams are used to capture, compare, and integrate the perceptions and mental models of a group of people. This approach helps a group to take a first step towards systemic policy by jointly setting the boundaries of the system of interest and exploring possible feedback structures.

In this appendix we present influence diagrams produced by the expert participants in a Climate-Energy-Water (CEW) Links workshop held at the Australian National University in March 2008. Individuals were given 15 minutes to map their own views concerning key variables and interactions within the Australian CEW system, and then participants worked in pairs to blend their individual diagrams. Pairs were given 30 minutes to complete this second step.

These diagrams express preliminary hypotheses about possible dominant feedback structures within the CEW system. Taken together they provide a first glimpse of the interactions that need to be accommodated in a more systemic approach to assessing the complex interactions between climate change, energy consumption, and water consumption.

The diagrams were produced by A. Campbell, L. Carroll, E. Craswell, C. Davis, S. Duus, K. Hussey, J. Lindesay, D. Marsh, B. Newell, J. Pittock, R. Prowse, M. Roderick, P. Rowland and N. Stenekes.

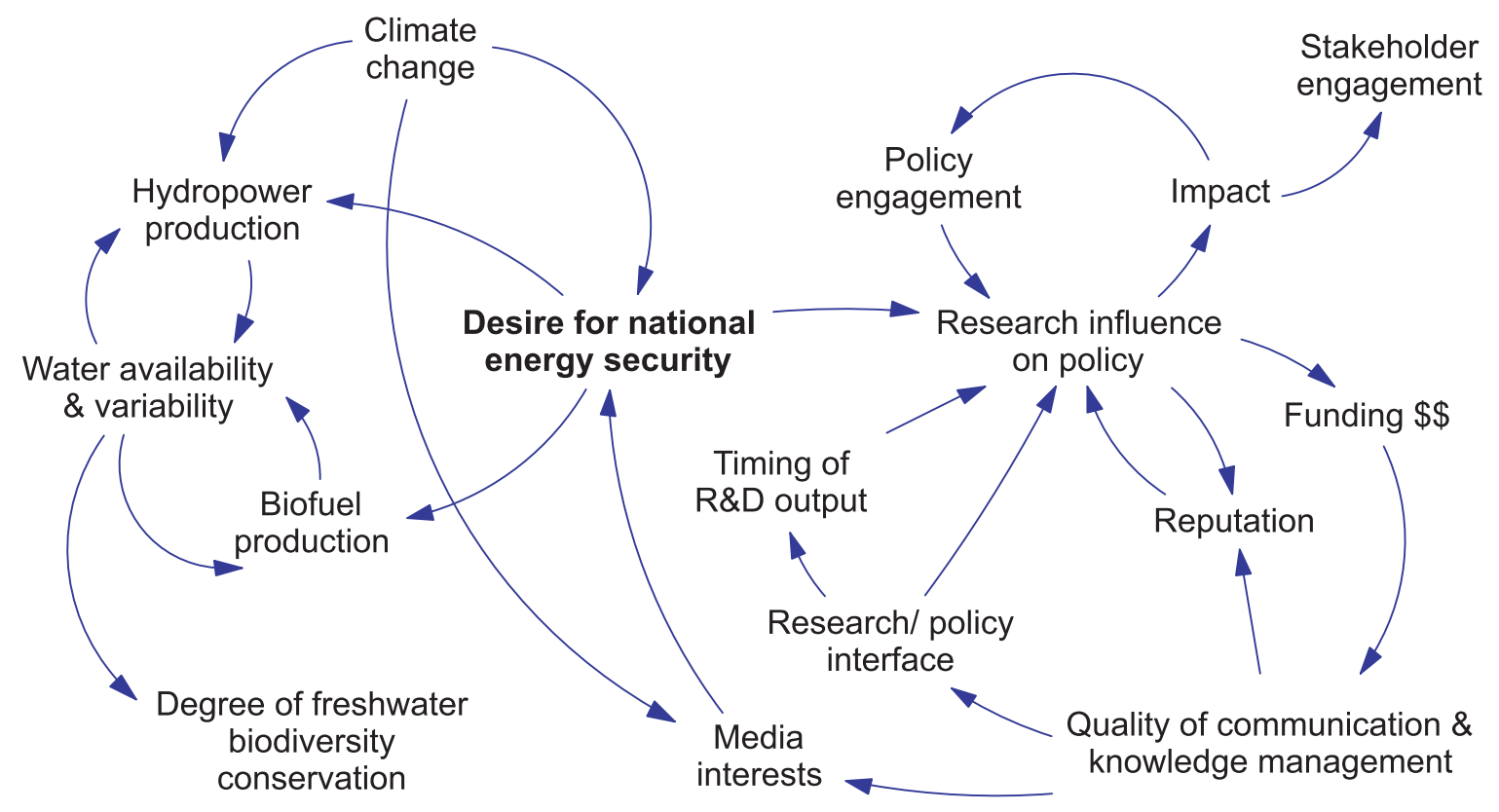

Figure A1 


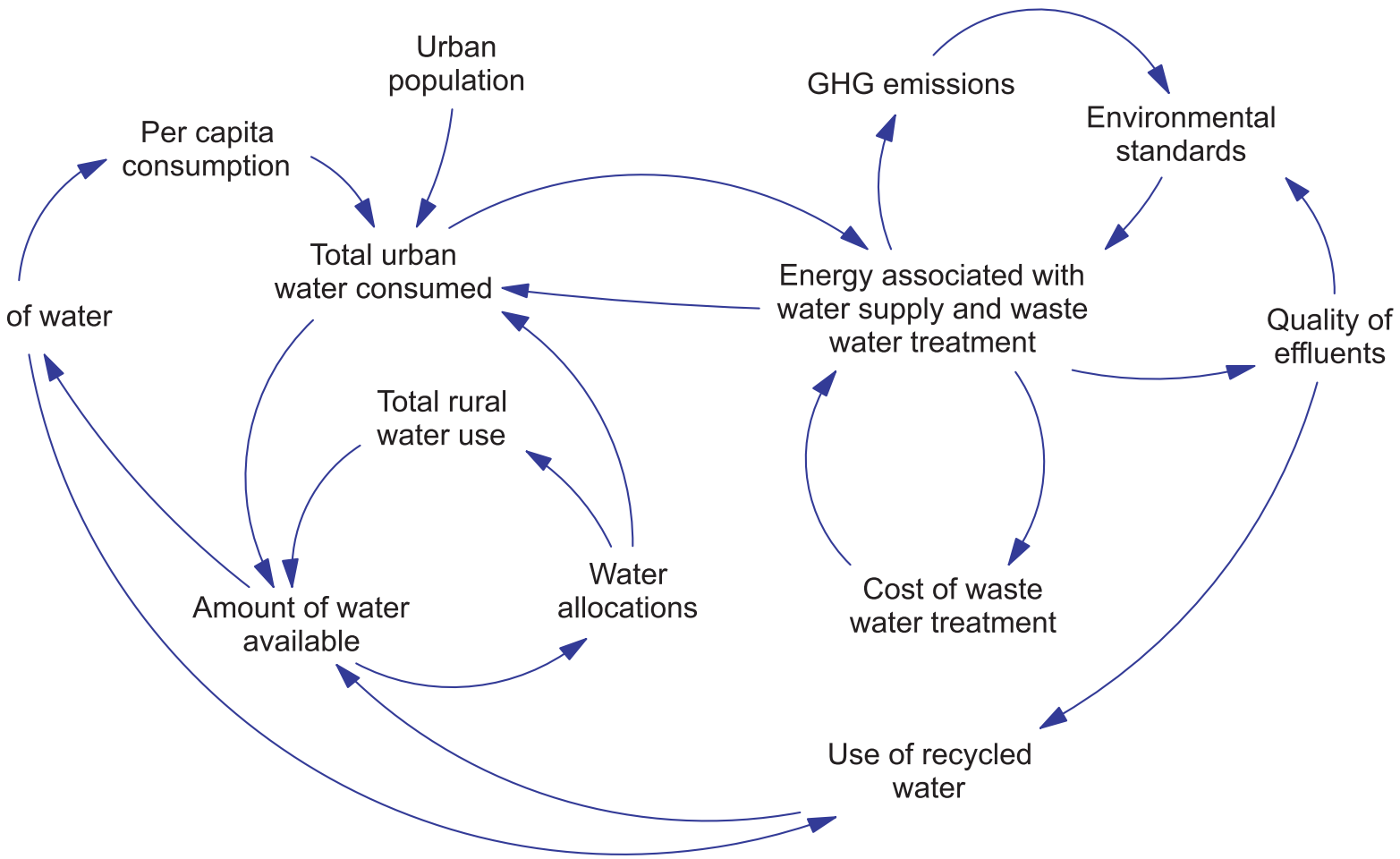

Figure A2

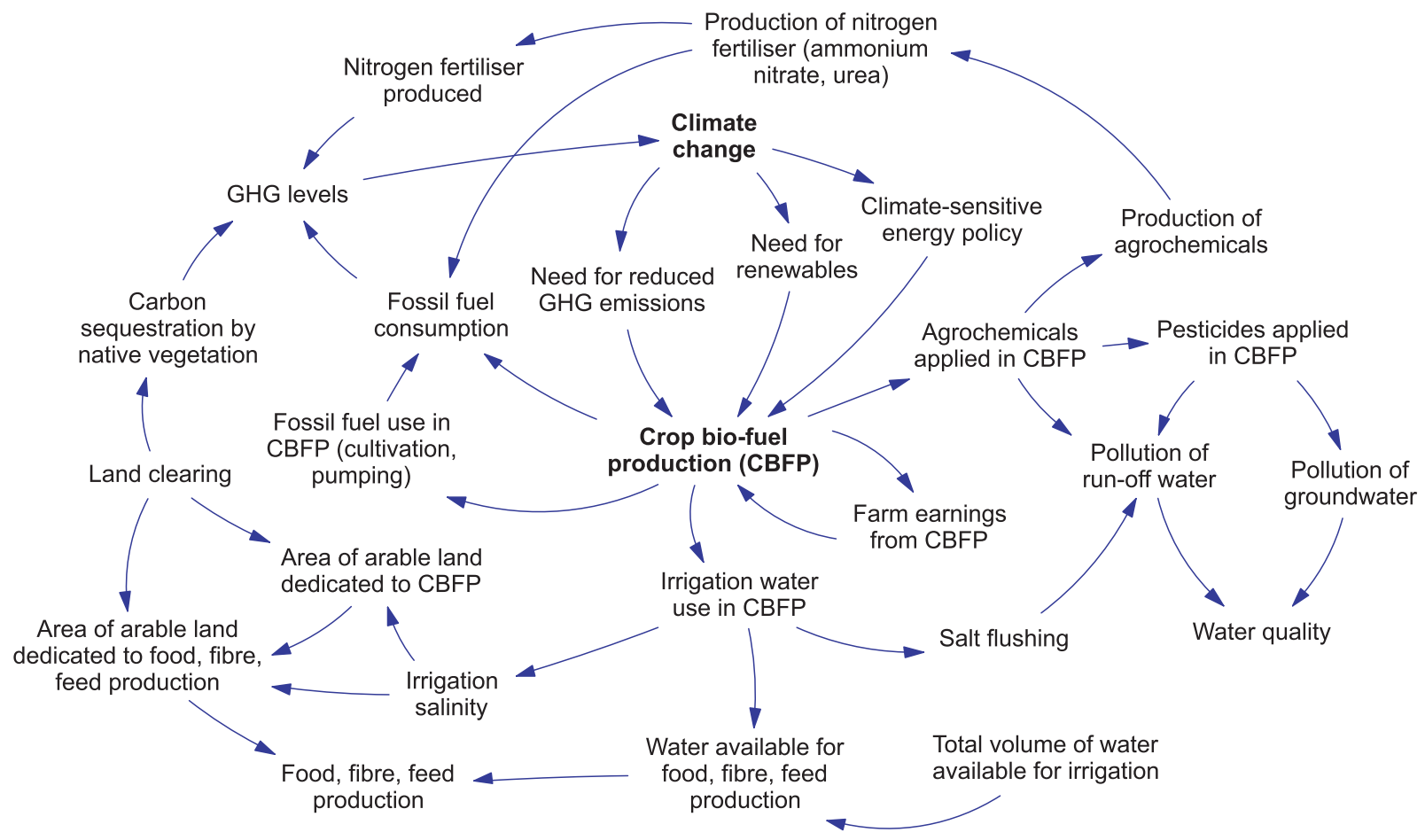

Figure A3 


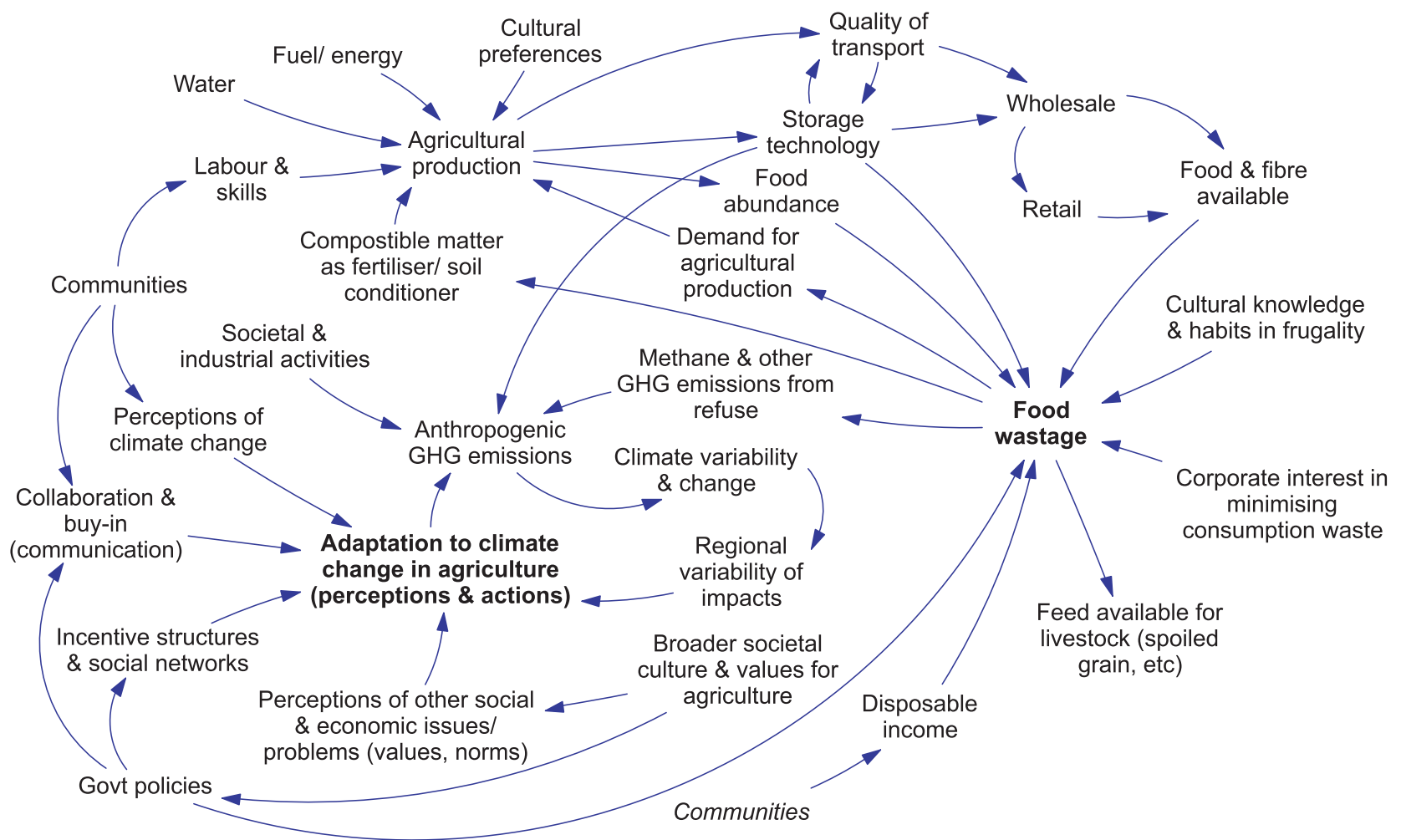

Figure A4

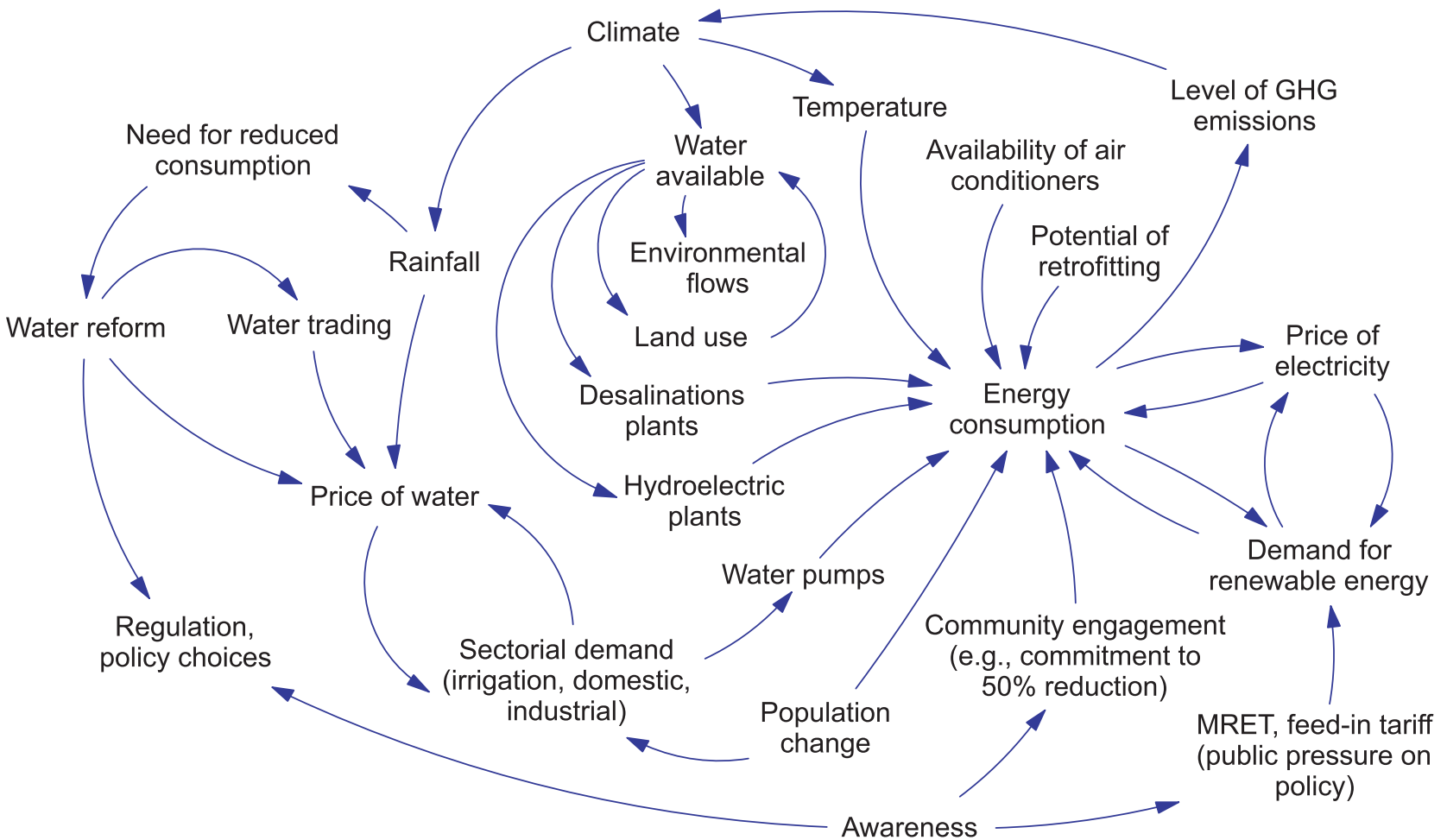

Figure A5 
Solar radiation

Evapotranspiration water

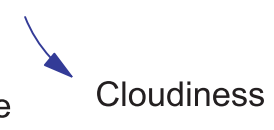

Cloudiness

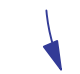
weather

Temperature gradients, sea surface temperature

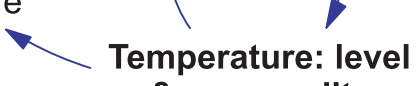

Precipitation: amount \&. seasonality

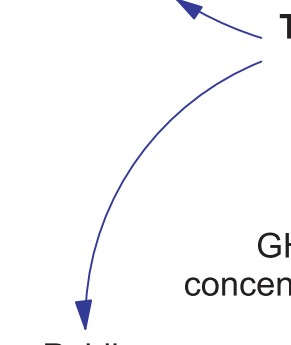

Public awareness \& seasonality

centrations

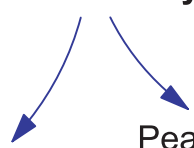

Peak demand

Soil moisture
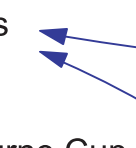

Melbourne Cup (social influence)
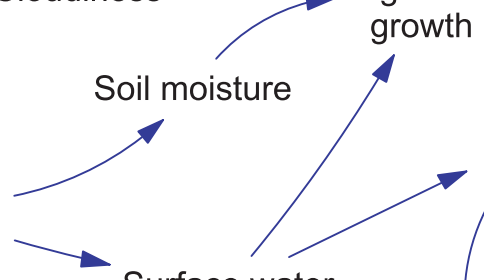

Crop

production

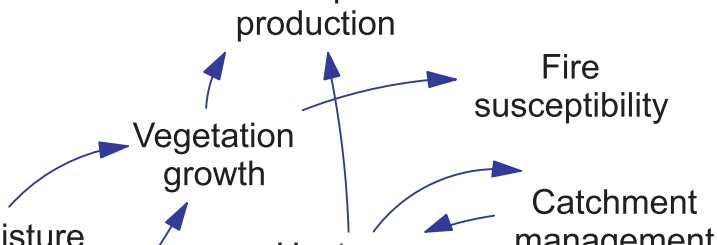

urface water

pstream irrigation

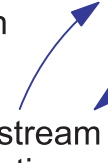

Downstream
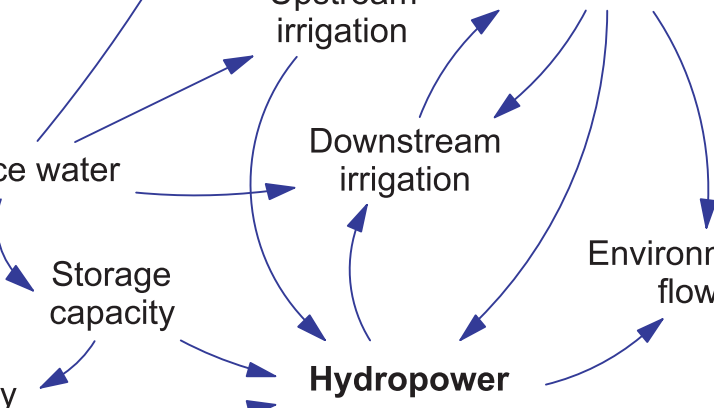

Environmental availability

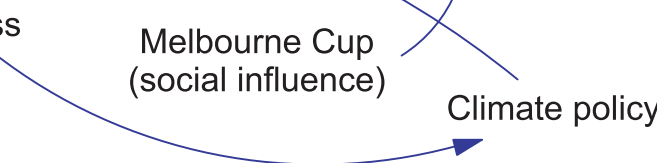

Spot price
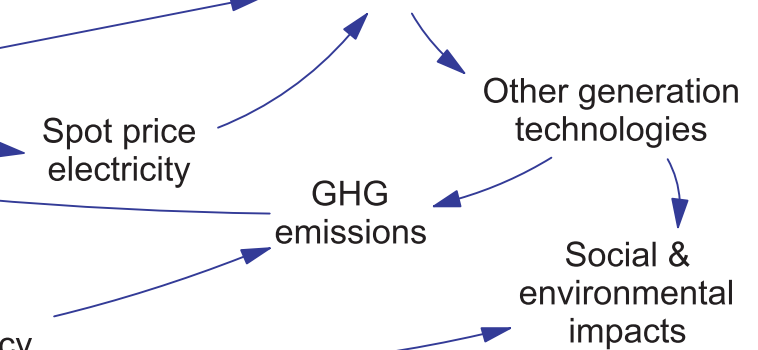

Figure A6

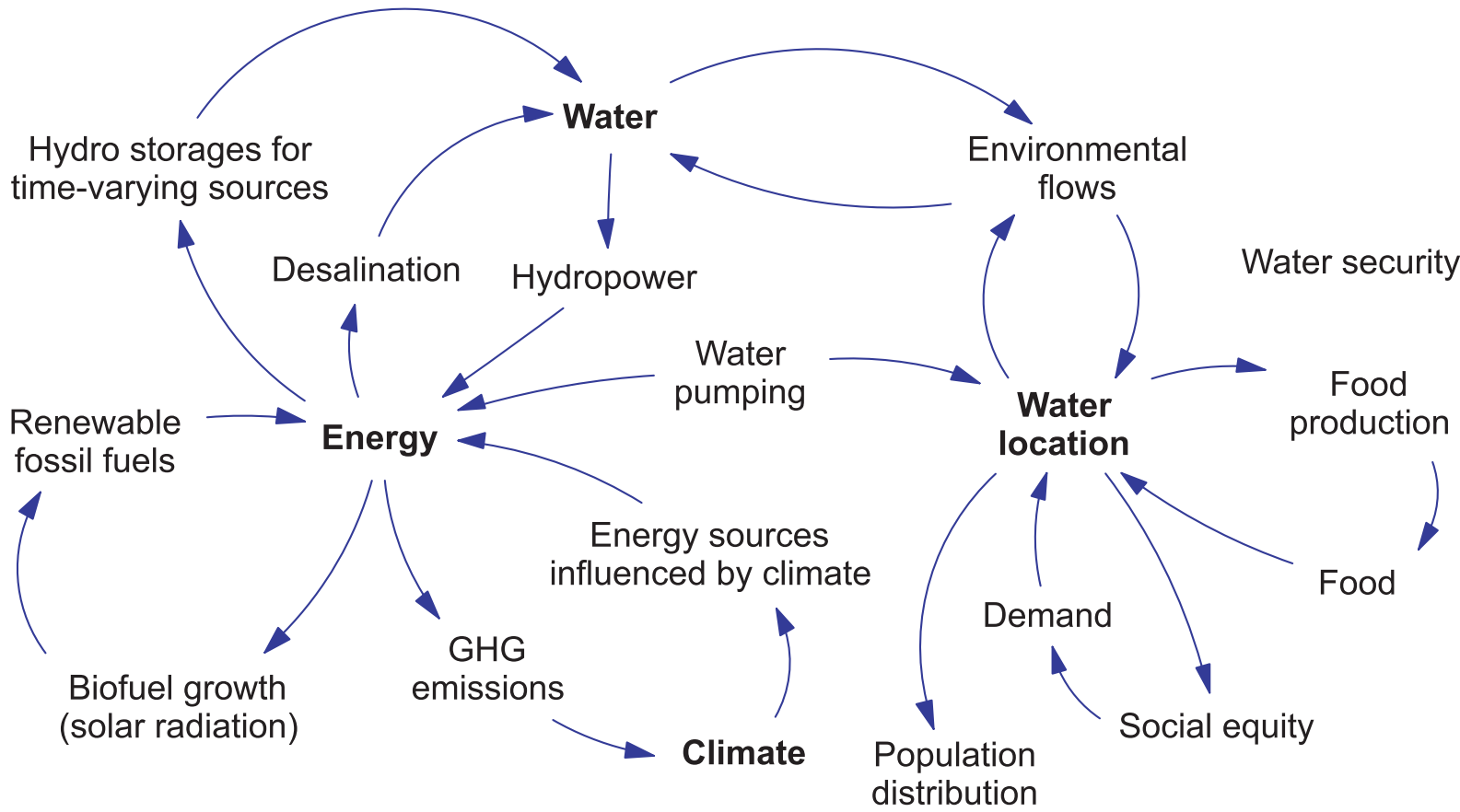

Figure A7 